\title{
AWARENESS OF FOLIC ACID USE AND ITS EFFECTS AMONG MEDICAL STUDENTS IN UKRAINE
}

DOI: 10.36740/WLek202109102

\author{
Kateryna Hlushko, Oksana Boyarchuk, Maria Kinash, Emillia Burbela, Yana Rohalska, Lesia Dobrovolska \\ I. HORBACHEVSKY TERNOPIL NATIONAL MEDICAL UNIVERSITY, TERNOPIL, UKRAINE
}

\begin{abstract}
The aim: To evaluate the awareness of folic acid, its use and effects, general knowledge about neural tube defects among medical students in Ukraine.

Materials and methods: This cross-sectional survey was conducted by questioning 114 fourth and fifth years'students of the Faculty of Medicine. The questionnaire contained questions about folic acid, its dietary sources, effects and periconceptional uses; spina bifida and its main symptoms.

Results: Overall, $96.5 \%$ of students knew that folic acid was a vitamin and $95.6 \%$ were aware of the one natural product which had a high folate level. However, awareness of its amount in different products was insufficient. Overall, $86.8 \%$ of surveyed knew that folic acid deficiency during pregnancy caused the congenital malformations. The knowledge of the synthetic folic acid supplementation before and during pregnancy was low (67.5\% and $53.5 \%$ respectively). Only $10 \%$ of women among medical students consumed folic acid regularly.

Conclusions: Despite the high level of general knowledge about folic acid and its effects among medical students in Ukraine, there is a poor awareness of the pre-conception administration of folic acid, and the number of people who regularly take folic acid among the respondents was very low.
\end{abstract}

KEY WORDS: awareness; children; folic acid; spina bifida; students

Wiad Lek. 2021;74(9 p.l):2033-2038

\section{INTRODUCTION}

Widening knowledge about the effects of folic acid (FA) and its periconceptional supplementation is an important medical problem due to spina bifida remains one of the most common non-chromosomal birth defects. The incidence of neural tube defects (NTDs) ranges from 0.4 to 1.6 in European countries; on average, one child per 1000 live births is affected worldwide [1], and rise to 4-9 per 1,000 live births in some countries [2-4]. According to US data it occurs in about 3,000 newborns annually, and in the UK about 500 pregnancies are affected [2-5]. In Ukraine, an exact estimate of the prevalence of neural tube defects remains unknown. This also applies to some other countries [6].

The NTDs include any malformation of the embryonic brain and/or spinal cord such as anencephaly, spina bifida and others [2]. Depending on the location and form of the defect, the course of the disease can range from mild to severe. The open forms of spina bifida are manifested by motor disorders, decreased sensitivity, bladder and bowel dysfunction and others. In closed forms, patients may not even know about the presence of the disease, or symptoms are mild. The NTDs in the most of cases are caused by FA deficiency and in about $10-30 \%$ it forms due to other reasons such as obesity, hyperglycemia, antiepileptic medicines intake, genetic factors, radiological impact, etc $[1,7]$.

FA is the water soluble form of vitamin B9 and its natural form which called folate is contained in leafy green vegetables, liver and others [6]. FA is an important nutrient during pregnancy and child 's periods of rapid growth.

Folates are involved in a wide range of vital processes, such as amino acid transformation, including homocysteine transformation to methionine; DNA/RNA synthesis, the formation of red blood cells and the body cells (stimulation of erythropoiesis), regeneration of muscles, and the development of rapidly growing tissues such as skin, mucous membrane of the gastrointestinal tract and bone marrow $[2,8]$. Folic acid has a protective role during pregnancy against teratogenic factors effects on the fetus and is involved in the normal maturation and functioning of the placenta. The FA deficiency causes increasing concentration of homocysteine inside the cells and its general plasma level while methionine level decreases [7, 9]. Hyperhomocysteinemia is strongly associated with microcirculatory disorders, risk of thrombosis, endothelial dysfunction, it has toxic and atherogenic effects, which lead to an increased risk of a different of pathological processes including birth defects (NTDs, Down syndrome), chronic heart diseases and others $[8,10]$. Folate deficiency during pregnancy is often associated with different adverse pregnancy outcomes such as miscarriage, preeclampsia, premature birth, antenatal fetal death, fetal growth restriction, fetal malformations and others [10].

The importance of preconceptional FA supplementation is that NTDs are formed between the 21st and 28th days of embryonic development, that is, when the woman does not 
know about a pregnancy yet $[3,7]$. And it's considerably because lots of pregnancies worldwide remain unplanned. For example, according to Centers for disease control and prevention about $50 \%$ of pregnancies in US are unplanned [11]. While in many countries including Ukraine an exact statistic of the amount of unplanned pregnancies is absent. Due to these facts American Academy of Pediatrics and Centers for Disease Control and Prevention recommend that all women of childbearing age who are capable of becoming pregnant should take $0.4 \mathrm{mg}$ of folic acid daily [ 7 , $9,11]$. This can prevent spina bifida formation in $50-70 \%$ of cases if unplanned pregnancy happens. In addition, if a woman has already had affected pregnancy or has had a history of child or fetus with NTD she should consume a folic acid in a higher dose $-4 \mathrm{mg}$ of folic acid daily, starting 1 month before becoming pregnant and throughout the first 3 months of pregnancy $[9,12]$.

But according to different surveys the most of women are not aware of this recommendations and at the best case scenario they start taking FA after visiting prenatal care; some part of them choose not to follow the recommendation due to various reasons or they take it sporadically. In addition, lots of women of childbearing age do not follow rational nutrition or have some medical issues which reduce FA absorption or disrupt its metabolism. These led to implementation of food fortification policy by many countries including the USA, which significantly reduced the incidence of the NTDs $[6,7]$. Such common and cheap food as bread, flour, pasta, cereals are fortified. Nevertheless, food fortification still is not obligatory in many countries including Ukraine.

\section{THE AIM}

The aim of the work was to evaluate the awareness of medical students about the folic acid use, its food sources and an impact on a pregnancy.

\section{MATERIALS AND METHODS}

This cross-sectional survey was conducted among students of Medical Faculty during June, 2019. The 114 students participated in the study: 40 (35.1\%) students of fourth and 74 $(64.9 \%)$ students of fifth years of study. Verbal consent was obtained before conducting the questionnaire survey; the participants were informed of the reasons why the information would be collected and how it would be used. They were assuring that their answers were anonymous and confidential.

A self-administered questionnaire, which contained twenty-six questions about the definition of folic acid, the food sources of this vitamin and the effects of its deficiency during pregnancy, the essential dosages of synthetic folic acid before and during pregnancy, spina bifida and its main symptoms was filled in. Also, there were obtained such data as an age, gender and place of living. The questionnaire was designed by the researchers.

The statistical analysis was done by using parametric and non-parametric methods. The qualitative date was com- pared by the Pearson's Chi-square $\left(\chi^{2}\right)$ test. The $p$-value less than $<0.05$ was accepted as a level of significance. Statistical analyses were performed by using computer based software "STATISTICA", version 10.0.

\section{RESULTS}

The majority of surveyed were female $(\mathrm{n}=87,76.3 \%)$ and only $23.7 \%(n=27)$ were male. Female to male ratio was 29:9. All the interviewed women were non-pregnant and all respondents did not have any children. The mean age of the respondents was $21.6 \pm 1.1$ years, ranged from 20 to 26 years. Out of $114,35.1 \%(n=40)$ were 4 -th course of study and $64.9 \%(n=74)$ were 5 -th course of study. The most of surveyed lived in towns $(84.2 \%, \mathrm{n}=96)$ and only $15.8 \%(\mathrm{n}=18)$ lived in villages.

Almost all respondents (96.5\%) were aware that folic acid is a water-soluble vitamin B9 and only $3.5 \%$ gave the wrong definition and answered that it is a hormone or a fatty acid $(\mathrm{p}<0.01)$.

Overall, $95.6 \%$ of students correctly noted at least one product that had the highest folate level. Nevertheless, the assessment of knowledge about each separate food product showed different results. The majority of students answered correctly that milk (91.2\%), grains (80.7\%) and fish (64.9\%) have low concentration of folate. In the same time, only $31.5 \%$ knew that yellow fruits and vegetables are reach in folate, which was significantly less in comparison to leafy green vegetables $(\chi 2=14.9, \mathrm{p}<0,001)$ (Fig. 1).

Table I presents information concerning the rational nutrition, folic acid deficiency and their impact on an embryo / a fetus. Overall, $99.1 \%$ of students replied that rational nutrition during pregnancy was important, however significantly less amount of respondents (63.2\%) answered that it also could have an impact on an embryo or a fetus $(p<0.001)$. The majority of respondents $(97.4 \%)$ knew that deficiency of folic acid could cause some pathology in a fetus or an embryo, but fewer students $(86.8 \%)$ pointed out that it, also, could lead to the congenital malformations in children $(\mathrm{p}<0.01)$. However, the number of those who did not know the ranged from $2.6 \%$ to $13.2 \%$ respectively, and the difference was significant $(\mathrm{p}<0.01)$.

Among other factors which can have a negative impact on the fetus the most of respondents pointed drugs (100.0\%), smoking (99.1\%) and alcohol (98.2\%). But awareness of other factors was significantly less (Table II). There were no differences in data depending on the year of study or gender.

Despite the fact that almost all (99.1\%) students believed eating rationally was important, significantly less (49.1\%) amount admitted that they followed it $\left(\chi^{2}=74.3, \mathrm{p}<0.0001\right)$.

Overall, $85.1 \%$ answered that they would plan to conceive whereas $13.2 \%$ did not think about it yet or did not want to do it. There were no differences between them in following rational nutrition. Out of 97 who would plan future pregnancy, only $49.4 \%$ declared that they eat rationally $(p>0.05)$. Out of 87 women, only $10.3 \%(n=9)$ admitted that they consumed synthetic FA regularly. 
Table I. The knowledge of students regarding rational nutrition and folic acid deficiency during pregnancy

\begin{tabular}{|c|c|c|c|}
\hline & $\begin{array}{c}\text { 4-th course } \\
(n=40)\end{array}$ & $\begin{array}{c}5 \text {-th course } \\
(n=74)\end{array}$ & $\begin{array}{c}\text { Total number } \\
(n=114)\end{array}$ \\
\hline \multicolumn{4}{|c|}{ Is a rational nutrition during pregnancy important? } \\
\hline Yes, n (\%) & $39(97.5 \%)$ & $74(100.0 \%)$ & $113(99.1 \%)^{*}$ \\
\hline No, n (\%) & $1(2.5 \%)$ & $0(0.0 \%)$ & $1(0.9 \%)^{*}$ \\
\hline \multicolumn{4}{|c|}{ Can a rational nutrition during pregnancy have an impact on an embryo or a fetus? } \\
\hline Yes, n (\%) & $26(65.0 \%)$ & $46(62.2 \%)$ & $72(63.2 \%)^{*}$ \\
\hline No, n (\%) & $14(35.0 \%)$ & $28(37.8 \%)$ & $42(36.8 \%)^{*}$ \\
\hline \multicolumn{4}{|c|}{ Does folic acid deficiency during pregnancy have an impact on an embryo? } \\
\hline Yes, n (\%) & $39(97.5 \%)$ & $74(100.0 \%)$ & $113(99.1 \%)^{*}$ \\
\hline No, n (\%) & $1(2.5 \%)$ & $0(0.0 \%)$ & $1(0.9 \%)^{*}$ \\
\hline \multicolumn{4}{|c|}{ Can folic acid deficiency during pregnancy lead to some diseases in the fetus? } \\
\hline Yes, n (\%) & $40(100.0 \%)$ & $71(95.9 \%)$ & $111(97.4 \%)^{*}$ \\
\hline No, n (\%) & $0(0.0 \%)$ & $0(0.0 \%)$ & $0(0.0 \%)^{*}$ \\
\hline I do not know, n (\%) & $0(0.0 \%)$ & $3(4.1 \%)$ & $3(2.6 \%)^{*}$ \\
\hline \multicolumn{4}{|c|}{ Can folic acid deficiency during pregnancy lead to congenital diseases in the fetus? } \\
\hline Yes, n (\%) & $31(77.5 \%)$ & $59(79.7 \%)$ & $90(78.9 \%)^{*}$ \\
\hline No, n (\%) & $4(10.0 \%)$ & $5(6.8 \%)$ & $9(7.9 \%)^{*}$ \\
\hline I do not know, n (\%) & $5(12.5 \%)$ & $10(13.5 \%)$ & $15(13.2 \%)^{*}$ \\
\hline
\end{tabular}

* - significant p-value $<0.05$.

Table II. The distribution of other negative factors that can affect pregnancy

\begin{tabular}{ccc}
\hline \multirow{2}{*}{ Negative factor } & \multicolumn{2}{c}{ Positive answer $(\mathbf{n = 1 1 4})$} \\
\cline { 2 - 3 } & $\mathbf{n}$ & $\%$ \\
\hline Drugs & 114 & 100.0 \\
\hline Smoking & 113 & 99.1 \\
\hline Alcohol & 112 & 98.2 \\
\hline Some medicines & 106 & $93.0^{*}$ \\
\hline Late mother's age & 105 & $92.1^{*}$ \\
\hline Folic acid deficiency & 99 & $86.8^{*} \#$ \\
\hline Irrational nutrition & 72 & $63.2^{*} \#$ \\
\hline Number of gravidities & 43 & $37.7^{*} \#$ \\
\hline A break between pregnancies & 34 & $29.8^{*} \#$ \\
\hline
\end{tabular}

Notes:

* - significant p-value $<0.05$ in comparison to drugs using and smoking; $\#$ - significant $p$-value $<0.05$ in comparison to alcohol using.

Most of the students considered that it is necessary to take some vitamins before $(\mathrm{n}=100,87.7 \%)$ and during $(\mathrm{n}=103$, $90.4 \%)$ pregnancy $(\mathrm{p}>0.05)$. The majority of respondents believed that it should be B-group vitamins $(74.3 \%)$ whereas fewer students thought that it should be other vitamins or minerals: vitamin C (14.2\%), Iron (8.8\%) or others (2.7\%).

Overall, $67.5 \%$ answered that synthetic folic acid intake was essential during pregnancy, whereas $53.5 \%$ of students believed that it also should be before pregnancy $\left(\chi^{2}=4.7\right.$, $\mathrm{p}<0.05$ ) (Fig. 2).

Table III shows the answers concerning spina bifida, its definition and main symptoms. Significantly more students were aware about definition of spina bifida. Out of 114 , $71.1 \%$ knew that SB was a neural tube defect, while $28,9 \%$ gave wrong answer $(\mathrm{p}<0.05)$. The knowledge about main symptoms of SB was quite different, but it almost did not differ depending on the course of study.

The main source of information about FA and NTDs was teachers at university $(65.8 \%, \mathrm{n}=75)$. Significantly more students of 4 th course pointed out it $(88.9 \%, \mathrm{n}=32)$ in comparison with 5 th year $(71.7 \%, \mathrm{n}=43)(\mathrm{p}<0.05)$. Out of $114,12.3 \%$ got information from conferences or TV / radio, $11.4 \%$ - from brochures, $9.7 \%$ - from newspapers or magazines, $7.0 \%$ - from friends (only 5 th year students), $3.5 \%$ - from nurses.

\section{DISCUSSION}

Assessment of the awareness of various segments of the population about folic acid and its role in the development of neural tube defects is quite common worldwide. This suggests that despite an in-depth knowledge about this pathology, it remains widespread and affect the health of children and adults. Awareness evaluation for certain diseases allows identifying ways to improve knowledge for preventing and proper treatment of rare diseases [12-14].

Our study showed that student's general knowledge about FA, as we expected, was high as $96.5 \%$ answered correctly about it definition. General knowledge about FA among medical staff is very important as several studies performed in different countries showed that most women got their knowledge from doctors, nurses or midwifes [5, 15-17]. Our study shows that the main 
Table III. The knowledge of students regarding spina bifida

\begin{tabular}{|c|c|c|c|}
\hline & $\begin{array}{c}\text { 4-th course } \\
(n=40)\end{array}$ & $\begin{array}{c}5 \text {-th course } \\
\quad(n=74)\end{array}$ & $\begin{array}{l}\text { Total number } \\
(n=114)\end{array}$ \\
\hline \multicolumn{4}{|c|}{ What defect is Spina bifida of? } \\
\hline Neural tube, $\mathrm{n}(\%)$ & $33(82.5 \%)$ & $48(64.9 \%)^{*}$ & $81(71.1 \%)$ \\
\hline Vertebra, n (\%) & $3(7.5 \%)$ & $8(10.8 \%)$ & $11(9.7 \%)$ \\
\hline Spinal cord, n (\%) & $1(2.5 \%)$ & $7(9.5 \%)$ & $8(8.8 \%)$ \\
\hline Vertebra and spinal cord, $\mathrm{n}(\%)$ & $1(2.5 \%)$ & $1(1.4 \%)$ & $2(1.8 \%)$ \\
\hline I do not know, n (\%) & $10(25.0 \%)$ & $2(2.7 \%)^{*}$ & $12(10.5 \%)$ \\
\hline \multicolumn{4}{|c|}{ The functions of which systems and organs are affected in spina bifida patients? } \\
\hline Nervous, $\mathrm{n}(\%)$ & $37(92.5 \%)$ & $67(90.5 \%)$ & $104(91.2 \%)$ \\
\hline Urinary/excretory, n (\%) & $20(50.0 \%)$ & 47 (63.5\%) & $67(58.8 \%)$ \\
\hline Musculoskeletal, n (\%) & $19(47.5 \%)$ & $36(48.7 \%)$ & $55(48,2 \%)$ \\
\hline Cardiovascular, n (\%) & $10(25.0 \%)$ & 31 (41.9\%) & $41(36.0 \%)$ \\
\hline Digestive, n (\%) & $13(32.5 \%)$ & $11(14.9 \%)^{*}$ & $24(21.1 \%)$ \\
\hline Respiratory, n (\%) & $4(10.0 \%)$ & 14 (18.9\%) & $18(15.8 \%)$ \\
\hline Vision, n (\%) & $3(7.5 \%)$ & $6(8.1 \%)$ & $9(7.9 \%)$ \\
\hline
\end{tabular}

* - significant $p$-value $<0.05$ between 4 -th and 5 -th course.
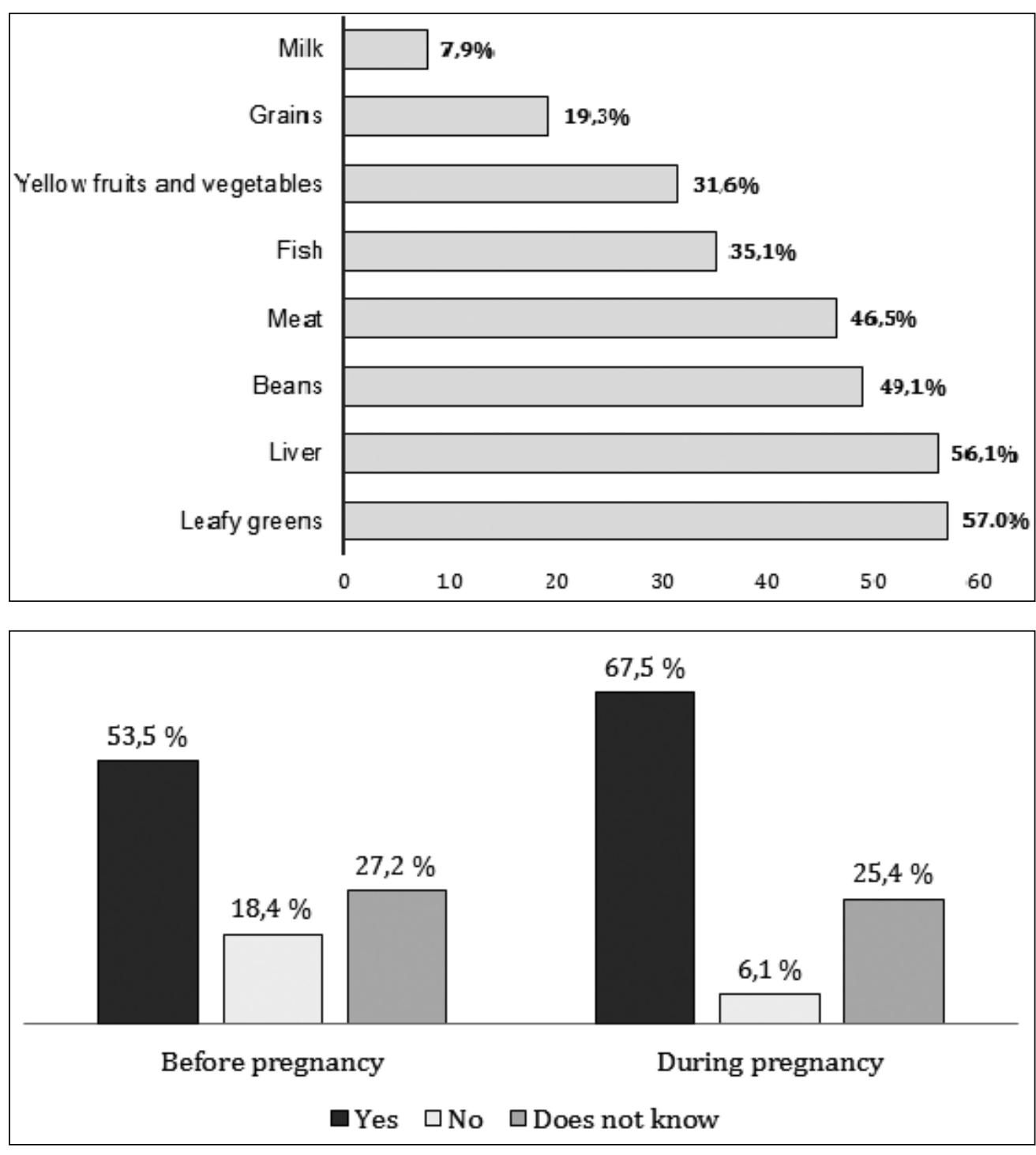

Fig. 1. Student's responses regarding the highest food sources of folate

Fig. 2. The necessity of additional synthetic folic acid intake before and during pregnancy according to student's answers 
source of information about FA was university teachers $(65.8 \%)$, while mass media were informative only in $21.9 \%$. It can be important for women without special education who getting information from another sources. In the same time, the survey performed in Netherlands by Temel et al. (2015) showed that despite of informational campaign about folic acid supplementation common knowledge about it remained low [16].

According to separate studies, general knowledge about FA was spread differently worldwide. For example, $18.2 \%$ of women in Saudi Arabia according to Alreshidi et al. (2018) were aware of FA (15), 35.8\% in China, 95\% in Canada, $98 \%$ in the UK, $42,2 \%$ in Turkey $[2,5]$ whereas from $92 \%$ to $100 \%$ of medical students in Slovakia according to Horn et al. (2014) [1] and $90.2 \%$ of medical students in Poland [18]. Also, lots of the researchers pointed out that general knowledge depended from the place of residence, educational level and total income [2, $5,15,16]$. For example, a study of Baykan et al. (2011) showed that $53.7 \%$ surveyed women who did not hear about folic acid in mostly cases were older than 35 and were less-educated [17].

Our research revealed that despite almost all (97.4\%) of students knew that FA deficiency could affect an embryo or a fetus, fewer $(86.8 \%)$ of them were knowledgeable that FA also prevented NTDs. For comparison, about $80 \%$ of women in Saudi Arabia were knowledgeable about it [15], $42-52 \%$ in the UK [5], $17 \%-27 \%$ of women and $83 \%-88 \%$ of medical students in Slovakia [1] and $90.2 \%$ of medical students in Poland (18); only $23.7 \%$ of women in Korea [6] and $18.3 \%$ in Turkey [2] were aware. Nevertheless, a study of Alreshidi et al. (2018) showed that despite women mostly did not know that FA is a vitamin but they were aware that it can prevent NTDs and $84 \%$ said that they used FA during conception, but theirs study was performed in urban location [15]. The results of women with a low standard of living may vary.

Our survey indicated that $95.6 \%$ of students were knowledgeable about at least one folate-rich food product. But the awareness of separate folic acid food sources was not sufficient and ranged from $31.6 \%$ to $57.0 \%$. The study provided among pregnant women in the UK showed that between $36.6 \%$ and $43.9 \%$ of women knew the dietary sources of folic acid [5] and this level increased to 57.0 $66.0 \%$ in Slovakia [1]. The medical students in Slovakia were more aware (92.0\% of correct answers) about it [1]. Despite the quite high knowledge of FA food sources, we evaluated that about half of respondents did not follow rational nutrition, which increases the probability of FA deficiency in childbearing aged women. The rational nutrition is very important as there is no state policy of food fortification in Ukraine. According to the U.S. Department of Agriculture's Food Data Central (2019), beef liver, spinach and asparagus have the highest level of folate [19]. Also, it is contained in such products as beans, fruits, meat, eggs, seafood and others [12].

Our study showed that students were highly informed about such teratogenic factors as drugs (100.0\%), smoking
(99.1\%), alcohol (98.2\%), some medicines (93.0\%) and late mother's age (92.1\%). Significantly less of them were aware about negative impact of folic acid deficiency (86.8\%). Knowledge about irrational nutrition was moderate and about the impact of number of gravidities and a break between pregnancies was low.

Despite the fact that about $85.1 \%$ of students in our study would plan to conceive, less amount was knowledgeable that synthetic FA intake was essential during pregnancy $(67.5 \%)$, and even less $(53.5 \%)$ of them - before pregnancy. This is quite low rate for persons with specific education. At the same time, a study of Pietrzykowska-Kuncman et al. (2017) showed that only more than half of mothers with medical education used FA before pregnancy and there were no differences in pre-conceptional folic acid intake between medical and non-medical education groups in Poland, which can be due to the high percentage of unplanned pregnancies [20]. And according to others [18] only $14.9 \%$ of medical staff regularly supplemented their diet with FA. And our survey showed that only $10 \%$ of young women with medical education consumed synthetic FA regularly, which is quite low. Another studies show that information campaigns conducted to disseminate knowledge about folic acid in different countries did not produce the expected result. For example, study performed in Netherlands showed that the knowledge of preconceptional FA supplementation ranged from $30.7 \%$ only to $36.8 \%$ within an urban perinatal health program [16]. Also, study of Maher \& Keriakos (2014) showed that unplanned pregnancy, lack of awareness about FA intake especially during one month before pregnancy led to less reduction of NTDs prevalence over a 10-year period compared to what was expected [5]. The authors suggested to integrate the knowledge of FA use and its effects in the school sex educational program and into family planning consultation. These steps may be more effective but need further evaluation.

According to our results, the general knowledge about spina bifida was quite high as $89.5 \%$ were aware about it. Almost all students knew that nervous system is affected in this patients but significantly less of them were aware that urinary $(58.9 \%, \mathrm{n}=67)$ and digestive systems $(21.1 \%$, $\mathrm{n}=18)$ are affected too $(\mathrm{p}<0.01)$. For comparison, the study performed among polish medical students showed that majority of them had moderate level of knowledge (55.1\%) [18].

\section{CONCLUSIONS}

Despite the high level of general knowledge about folic acid and its effects among medical students in Ukraine, there is a poor awareness of the pre-conception administration of folic acid, and the number of people who regularly take folic acid among the respondents was very low.

The rising awareness of periconceptional folic acid supplementation among women and implementation of food fortification state program in Ukraine remains the considerable issues that need to be solved. 


\section{REFERENCES}

1. Horn F., Sabova L., Pinterova E. et al. Prevention of neural tube defects by folic acid - awareness among women of childbearing age in Slovakia. BratisI Lek Listy. 2014; 115 (2): 91-7. doi: 10.4149/BLL_2014_020.

2. Köken G.N., Derbent A.U., Erol 0. et al. Awareness and use of folic acid among reproductive age and pregnant women. JTurk Ger Gynecol Assoc. 2013; 14 (2): 87-91. doi: 10.5152/jtgga.2013.81594.

3. Kim M.J., Kim J., Hwang E.J. et al. Awareness, knowledge, and use of folic acid among non-pregnant Korean women of childbearing age. Nutr Res Pract. 2018; 12 (1): 78-84. doi:10.4162/nrp.2018.12.1.78.

4. Wallingford J.B., Niswander L.A., Shaw G.M. et al. The continuing challenge of understanding, preventing, and treating neural tube defects. Science. 2013; 339 (6123): 1222002. doi:10.1126/ science. 1222002.

5. Maher M., Keriakos R. Women's Awareness of Periconceptional Use of Folic Acid Before and After Their Antenatal Visits. Clin Med Insights Womens Health. 2014; 7: 9-15. doi:10.4137/CMWH.S13535.

6. Kim M.J., Kim J., Hwang E.J. et al. Awareness, knowledge, and use of folic acid among non-pregnant Korean women of childbearing age. Nutr Res Pract. 2018; 12 (1): 78-84. doi: 10.4162/nrp.2018.12.1.78.

7. Prevention of neural tube defects: results of the Medical Research Council Vitamin Study. MRC Vitamin Study Research Group. Lancet. 1991; 338 (8760): 131-137. doi: 10.1016/0140-6736(91)90133-A.

8. Tiutiunnyk V.L., Kurchakova T.A., Mikhailova 0.I. The use of folic acid as part of vitamin-mineral complex for the prevention of pregnancy complications. Russian Journal of Woman and Child Health. 2015; 20: 1205-1208. (In Russian).

9. Folic Acid for the Prevention of Neural Tube Defects. Committee on Genetics. Paediatrics. 1999; 104(2): 325 - 327. doi: 10.1542/ peds.104.2.325.

10. Hovdenak N., Haram K. Influence of mineral and vitamin supplements on pregnancy outcome. Eur J Obstet Gynecol Reprod Biol. 2012; 164 (2): $127-132$.

11. Centers for disease control and prevention. Folic acid. 2019. https:// www.cdc.gov/ncbddd/folicacid/about.html [access date 02.05.2020]

12. Folate. Fact Sheet for Consumers. The National Institutes of Health's Office of Dietary Supplements. 2019. https://ods.od.nih.gov/factsheets/ folate-Health\%20Professional/ [access date 02.05.2020]

13. Boyarchuk 0., Volyanska L., Kosovska T. et al. Awareness about primary immunodeficiency diseases among medical students. Georgian Medical News. 2018; 12 (285): 124 - 130.

14. Boyarchuk 0., Volokha A., Hariyan T. et al. The impact of combining educational program with the improving of infrastructure to diagnose on early detection of primary immunodeficiencies in children. Immunol Res. 2019; 67 (4-5): 390-397. doi: 10.1007/s12026-019-09103-w.

15. Alreshidi F.F., Almujil A.S., Malak A.S. Awareness of folic acid use among Saudi women attending outpatient clinics at King Fahad Medical City. J Family Med Prim Care. 2018; 7 (5): 957-962. doi: 10.4103/jfmpc. jfmpc_174_18.

16. Temel S., Erdem Ö., Voorham T.A. et al. Knowledge on preconceptional folic acid supplementation and intention to seek for preconception care among men and women in an urban city: a population-based crosssectional study. BMC Pregnancy Childbirth. 2015; 15:340. doi:10.1186/ s12884-015-0774-y.
17. Baykan Z., Oztürk A., Poyrazoğlu S. et al. Awareness, knowledge, and use of folic acid among women: a study from Turkey. Arch Gynecol Obstet. 2011; 283 (6): 1249-53. doi: 10.1007/s00404-010-1547-5.

18. Milewska N.N., Przysada G., Perenc L. et al. Assessment of knowledge of female students from the Medical Department of the University of Rzeszow regarding isolated neural tube defects. Advances in Rehabilitation. 2016; 2: 39 - 47. doi:10.1515/rehab-2015-0042.

19. Food Data central. U.S. Department of Agriculture, Agricultural Research Service. 2019. https://fdc.nal.usda.gov/index.html [access date 02.05.2020]

20. Pietrzykowska-Kuncman M.,Zasina-Olaszek D., Łukasz K. et al. Intake of folic acid by Polish women with higher education - a survey research: can we do more? Ginekol Pol. 2017; 88 (8): 428-433. doi: 10.5603/ GP.a2017.0079.

The work is a fragment of departmental scientific research work "Clinical and pathogenic features of the course, diagnosis, treatment and prevention children's socially significant diseases".

\section{ORCID and contributionship:}

Kateryna Hlushko: 0000-0002-4777-5300 A-D

Oksana Boyarchuk: 0000-0002-1234-0040 A,C,E,F

Maria Kinash: 0000-0002-4380-977X ${ }^{B}$

Emillia Burbela: 0000-0002-8439-2966 ${ }^{B}$

Yana Rohalska: 0000-0002-6376-1953 ${ }^{B}$

Lesia Dobrovolska: 0000-0002-4155-534X ${ }^{C}$

\section{Conflict of interest:}

The Authors declare no conflict of interest.

\section{CORRESPONDING AUTHOR \\ Kateryna Hlushko}

I. Horbachevsky Ternopil National Medical University

1 Maidan Voli, 46001 Ternopil, Ukraine

tel: +380976367234

e-mail: glushko_kt@tdmu.edu.ua

Received: 17.08 .2020

Accepted: 02.06.2021

A - Work concept and design, B - Data collection and analysis, C - Responsibility for statistical analysis, D-Writing the article, $\mathbf{E}$-Critical review, $\mathbf{F}$ - Final approval of the article 